\title{
Fighting Talk - Martial Arts Discourse in Mainstream Films
}

\section{Introduction}

This chapter examines conversations, dialogues and statements about martial arts in films that can by no stretch of the imagination be regarded as martial arts films. It does this in order to glean insights into the status of martial arts in mainstream popular culture. As such, although it is a study that reads and takes evidence from films, its concerns are not those of the discipline of film studies. Rather, it is interested in the ways that martial arts are understood, positioned, and given value within the wider flows, circuits, networks or discourses of culture. As well as offering a discrete analysis of martial arts discourse as registered in film dialogue, this chapter also serves as a recapitulation and reiteration of the overarching poststructuralist or deconstructive theoretical framework that has organised this book.

The premise here is that mainstream, non-specialist films in which dialogue about martial arts occurs can be regarded as texts that relate to, arise from, register, and feed back into wider understandings of and opinions about martial arts. This is especially the case for films set in the contemporary world and which implicitly make some kind of claim to having some kind of relationship with realism (even if they are comedies).

Of course, there is no simple mapping of or direct relation between representation and reality here. A statement or conversation offered in a fiction film does not simply reflect or recount opinions circulating in face-to-face or online conversations among real people in the 'real world'. However, in all communicative processes, sense can only be made of utterances that employ shared ideas, familiar conventions, and so on, even if a new utterance (e.g., a conversation in a film) brings in unique, new or surprising elements, formulations, or

How to cite this book chapter:

Bowman, P. 2019. Deconstructing Martial Arts. Pp. 125-146. Cardiff: Cardiff University

Press. DOI: https://doi.org/10.18573/book1.h. License: CC-BY-NC-ND 4.0 
combinations of elements. So, the premise of this study is not that film dialogue simply maps, reflects or expresses established cultural values in straightforward ways; rather, the premise is that film dialogue registers, reworks, reiterates and replays familiar cultural values in complex and creative ways - but ways that always seek to 'make sense' by relating to, playing around with and reworking established ideas and values.

It is in this way that this study seeks to explore and cast light on the 'discursive status' of martial arts in Anglophone popular culture. Given the necessarily interdisciplinary approach and orientation of this work, something should be said first about the notion of discourse and the theory of discourse as it functions in this work, before turning our attention to the discussion of martial arts in non-martial arts film.

\section{Popular Cultural Discourse}

Michel Foucault argued that the 'regularity in dispersion' of certain types of statement about an object, phenomenon or practice have a structuring effect on what that object, phenomenon or practice is deemed to be. They influence how it is understood, thought about, related to and treated in cultural, political and institutional discourses (Foucault 1972; Deleuze 2006; Widder 2008). Multiple schools of thought have developed in the wake of this, including several species of discourse theory (Akerstrøm Andersen 2003). A key premise of most of these is that the connotations, meanings and values permeating and congregating around (perhaps) anything are determined at least in part by wider representational tendencies (Barthes 1972; Stuart Hall and et al 1997; Laclau 2000; Bowman 2007). There are disagreements about the details, but all schools of discourse analysis concur that key instances, contexts, styles and genres of representation at least 'influence' (and sometimes actually 'produce') the way things are thought about, imagined, and related to - and even what they are deemed to 'be' (Derrida 1982; Laclau and Mouffe 1985; Said 2000).

Regardless of whether or not one or another theory of discourse adequately captures how human societies 'really work', it is certainly the case that between the 1970s and 1990s the concept or metaphor of discourse (along with such related concepts as 'representation' and 'textuality') entirely reorientated the paradigms and approaches of numerous academic fields, and even helped to generate new ones (Hall 1992; Mowitt 2003; Bowman 2015a). Indeed, in this sense, the notion of discourse itself generated considerable discourse. In Foucault's own terms, the notion of discourse arguably became what he would have termed a 'founder of discursivity' in its own right (Foucault 1991). It is something that generated new thoughts, new words and new practices.

Although developed conceptually in the 1970s and 1980s, it is still not uncommon for academic subjects of all kinds to conceptualise the world as discourses made up of texts. Texts are the constructs that come out of and feed 
back into discourses. The 'textual paradigm' and/or the 'discourse approach' can be regarded as organising and structuring the focus and language of a great deal of academic work in the arts, humanities and social sciences (Mowitt 1992; Bowman 2007).

This present study is to be situated within this tradition, although it proceeds in full awareness of the complexity, uncertainty and problems associated with both textual and discourse approaches (Hall 1992; Mowitt 1992; Bowman 2007, 2008). Some of these problems include disagreement among scholars about where and how discourses are to be pinpointed or demarcated; whether they exist principally at the level of representation (Said 1995; Young 2001) or at the level of institutional policies, laws and legislations (Foucault 1977; Young 2001); whether they principally relate to the realm of public media (Fairclough 1995) or every micro and macro level of modern human life (Arditi and Valentine 1999); in which direction 'causality' runs in discourses - that is, whether representations are the causes of things (from attitudes and beliefs to policies) or whether other things (from attitudes and beliefs to policies) are the causes of representations (Krug 2001; Judkins 2014b; Barrowman 2015b); and so on. There is a great deal of what arch-theorist of textuality Jacques Derrida would call 'undecidability' in these waters (Derrida 1981). But what all scholars of discourse studies can be said to agree upon is the tenet of the significant cultural, political, and even ontological power of representations.

Following the broadly political orientations of many of the founding theorists of discourse studies, the dominant tendency within all schools of discourse analysis has been to maintain an explicitly political focus. Hence discourse analyses tend either to choose explicitly political topics (for example, the media coverage of elections) and to subject them to further political interrogation, or they take 'cultural' topics (like the practices and identities of everyday life) and unearth the political dimensions of these topics (Laclau 1994; Torfing 1998). In this sense, discourse studies tend to produce insights into the 'political' bias or orientation of whatever is examined.

Yet, despite the inescapably 'politicizing' effect that the notion of discourse produces in its focus on the contingency, variability and hence changeability of the human world, there is no necessary reason why discourse studies and discourse analysis should have an explicitly, directly or literally political starting point or end point. Indeed, precisely because the notion of discourse already presumes the immanently political character of (potentially) everything (Arditi and Valentine 1999; Marchart 2007), employing it to reveal ever more political aspects to ever more areas of life is perhaps not the most interesting or challenging thing to do when employing it at this time. Perhaps scholars no longer need to belabour the inevitable conclusions about the political dimensions of things. This is a conclusion that discourse analysis can easily reach (Hall 2002). For, given that discourse theories tend to posit that 'everything' in human social and cultural life is contingent and hence political, maybe to search for the political dimension and reach a political conclusion over and over again is predictable. 
But what else is to be done with a paradigm organised by the syllogism that everything is contingent, that contingency involves variation and change, and therefore everything is political ? $^{1}$ Is the political focus unavoidable?

The obligation for academic work to discover and rediscover the political dimensions of the world is heavy. Robert J.C. Young once argued that the imperative to focus on 'the political' has been the dominant 'architectonic' organising knowledge production in the arts, humanities and social sciences over at least the last half century (Young 1992). Similarly, Gary Hall notes that even though cultural studies has often claimed to be open to the study of any and all aspects of culture it has overwhelmingly tended to choose worthy political objects and refract everything through a 'politicizing' lens (Hall 2002). Rey Chow, too, notes that even the apparently non-political and firmly aesthetic/ cultural field of film studies became settled, stabilized, regularized and more firmly established when its dominant questions, concerns and themes became those of identity (and) politics (Chow 2007).

My current concern proceeds with all of this as its backdrop, but it also fights against aspects of it. The aim is not to paint martial arts as a continuation of politics by other means. ${ }^{2}$ Nor is it to look into specific, specialist, niche or actual martial arts contexts, fields or 'subcultures'. Indeed, it is resolutely not looking 'into' anything specifically martial arts 'proper' at all. This work does not look at what martial artists say, think or feel about themselves, in their own specialist contexts, such as blogs, vlogs, magazines, books, and so on. Rather, it is interested in establishing what non-martial artists feel, think and say about martial arts and about martial artists. The aim is to establish the range of ideas and values that circulate about martial arts, about martial arts practitioners, and about martial arts fans. The wider research project has so far taken in the realms of comedy, popular culture and journalism research (Bowman 2017a, 2017b). Here, my attention is on the discursive status of martial arts in film. Specifically, the focus is on films that could in no way be construed as martial arts films. My question is whether there are any patterns, repetitions, reiterations, or any 'regularity in dispersion' of discursive statements about martial arts outside of proper martial arts contexts.

\footnotetext{
${ }^{1}$ Moreover, as Freud most famously argued, there is a pleasure in repeating. In different ways and in different contexts, repetition produces stability, intelligibility, familiarity, and gives orientation. So, posing the same kinds of questions and rediscovering the same kinds of answers makes sense (in more than one way). Yet, must discourse analysis always and only rediscover the political, wherever it looks?

2 Many excellent studies have already carried out important work that has shown this, across a range of different historical and cultural contexts. I will not give a list of citations pointing to any of these works at this point, because I do not want to give the impression that such works only do this one thing. On the contrary, all good works of cultural studies (and martial arts studies) do much more than 'merely' this one thing. My point is simply that 'perceiving the political' continues to function as a reliable way to confer validity and legitimacy upon an academic orientation.
} 


\section{Methodological Matrix}

The importance of film to martial arts culture (and also to the status of martial arts within popular culture) cannot be overstated (Bowman 2017b). Filmic representations of martial arts have long been a key force in stimulating interest and participation in martial arts (Bowman 2010d, 2013b). Moreover, stylised martial artsy fights appear regularly in all kinds of films today. In other words, films certainly do not need to be 'martial arts films' to have martial arts within them. Indeed, the frequency of their appearance suggests that martial arts remain as popular and 'bankable' as they have been since the global 'kung fu craze' of the 1970s (Brown 1997). In Foucauldian terms, this proliferation and frequency of their reiteration in a range of different kinds of texts and different discursive contexts could constitute a 'regularity in dispersion'. Certainly, martial arts are a very familiar part of all kinds of films. This is so much so that they might be regarded as a standard feature of popular culture, a standard part of widespread 'normal' cultural literacy. People might be expected to 'know about' martial arts - albeit only at the level of recognition or acknowledgement if not 'knowledge' - in the same way that one might reasonably expect people to 'know about' ballet, say, or farming, witchcraft or drug dealing, for example. 'People' may never have experienced these things directly, but they more or less 'know' what they are. When this does not come from first-hand experience, it often comes from media representations.

Obviously, comparatively few people could be expected to be able to distinguish kung fu from karate or karate from taekwondo. Fewer still could be expected even to have heard of krav maga or escrima. But the majority of people could be expected to recognise 'martial arts' when they see them. If not unequivocally 'popular', then, martial arts are certainly part of 'the popular' (Hall 1994) - stitched into the current 'popular cultural formation' (Morris 2004; Morris, Li, and Chan 2005). So, the question is: Outside of martial arts films and films that can be said to be steeped in martial arts practitioner discourses, how are martial arts thought about and talked about?

\section{Blurred Lines}

In posing this question, the problem of how to demarcate and separate an inside from an outside immediately arises. There is a great deal of grey area around the category 'martial arts film'. It is unclear whether there is even a fixed or demarcated genre of martial arts film in the West. Certainly, many action films feature martial arts choreography. But, in trying to separate martial arts films from non-martial arts film, it may not prove possible to establish a stable boundary between, say, martial arts film, action film, action comedy, horror, and others. It is equally difficult to clinch the case of whether a film is mainstream, niche, cult, or some other designation. 
So, in attempting to establish anything about what we might conceptualise as the 'wider', 'mainstream', or 'popular' discursive status of martial arts in 'wider' (non-specialist) circuits of culture, we are facing a number of problems. All of these devolve on the problem of where or how to draw the line between specialist and non-specialist, martial arts and non-martial arts, mainstream and subcultural, and so on.

Rather than attempting to resolve such categorical and taxonomical conundra here, another option was chosen. This involved the decision to impose a radically simplifying and drastically clarifying border, one that may initially seem eccentric but that offered the benefits of being clear, stable, meaningful, and not easily problematized, jeopardised, made unclear, or deconstructed. This was the decision to focus on dialogue about martial arts in unequivocally non-martial arts films.

In applying such a principled limitation of focus, the first thing discovered was that, other than in martial arts and action films, martial arts are rarely discussed. They are often shown. There are often moves, gestures, visual allusions, and visual references. But conversations about martial arts are few and far between. Furthermore, in order to find such elements to analyse, there are no methodological shortcuts: One simply needs to know a lot about lots of films. There are no databases to dig into and no search terms that an internet search engine can return results for. Google doesn't understand what is being asked when search terms are phrases like 'dialogue about martial arts in non-martial arts films'. Even Americanising it by changing the word 'films' to 'movies' doesn't help. It was not possible to construct a search question with any mention of martial arts films in it that led anywhere other than to pages about martial arts films.

Having no database and unable to establish 'intelligible' search terms, the only recourse was to rely on memory and knowledge of as wide a range of films as possible. This returned a very limited number of results. So, the question was posed online, in several Facebook groups. Reasoning that people with an interest in martial arts would be most likely to remember references to martial arts in films, I focused my attention on the Martial Arts Studies Facebook Group, which had almost 1,000 members at the time (in early May 2017).

Interestingly (and perhaps significantly), it turned out that it is not just inhuman search engines that do not understand questions about 'dialogue about martial arts in films that are not martial arts films'. It was evident that the overwhelming majority of people asked could not quite get their heads around the question either. In fact, from among dozens of respondents, only one or two people actually understood the question. Most knowledgeable among them was film scholar Kyle Barrowman, who came up with a number of valuable suggestions, some of which I will discuss below.

However, the majority of people who understood the question suggested action films. Most people suggested The Matrix (1999). Unfortunately, it was clear that I had to exclude The Matrix because, even though many people don't seem to think of it as a martial arts film, it was choreographed by famous 
martial arts choreographer Yuen Woo Ping, it is choc-full of stylistically precise martial arts choreography, and (as I had discovered during my ill-fated internet searches) it regularly features in top tens of 'must see' martial arts films. The fact that people don't seem to recognise when a Hollywood action film becomes a martial arts film (or vice versa) perhaps says more about the porousness of these two supposed genre categories and the essential lack of a fixed and stable Hollywood martial arts film genre than anything else. So, The Matrix fell within this study's 'exclusion zone'. But some limit cases do deserve some attention and warrant some quick preliminary consideration.

\section{Liminal Cases}

In terms of Hollywood action films that feature martial arts, it seems significant to note that relatively few of them actually discuss martial arts. In mainstream US action films, martial arts are shown, not discussed. Very few action films with martial arts choreography in them even mention martial arts at all in the dialogue. To illustrate this, and the porousness of the borders between 'martial arts film' and 'action film' in the US context, let us briefly consider some wellknown examples, even though they are technically outside the parameters of this study.

One notable case is the amnesiac Jason Bourne (The Bourne Identity [2002], The Bourne Supremacy [2004], The Bourne Ultimatum [2007], Jason Bourne [2016]) who wonders aloud in The Bourne Identity why it is that he knows so much about combat, strategy, situational awareness, and survival despite not remembering who he is. However, other than one brief moment of musing, there is no specific dialogue about his ample fighting abilities. ${ }^{3}$ Elsewhere, long before the Bourne films, in Conan the Barbarian (1982) the titular warrior played by Arnold Schwarzenegger was sent to study with 'Eastern' sword masters, but it was only the extra-diegetic voiceover that told us this. There was some talk in Batman Begins (2005), reminiscent of Highlander (1986), of training and deception, but very little. And, it deserves to be noted, the 'action' film, Batman Begins, is structured by a martial arts (and) oedipal narrative of a once adopted and subsequently renegade (or 'ronin') ninja.

Similarly, the sci-fi fantasy Star Wars films have many of the hallmarks of Chinese martial arts wuxia pian, or swordplay drama (Feichtinger 2014). Some might call this cultural appropriation, or expropriation. From such a perspective, The Matrix can either be regarded as a trailblazing Western 'heir' to the Hong Kong style of 'wire-fu' fight choreography that prepared Western audiences for the aesthetics of the subsequently successful Crouching Tiger, Hidden Dragon and subsequent transnational wuxia pian 'wire-fu' films, or it can be

\footnotetext{
${ }^{3}$ In terms of Jason Bourne's fighting style, The Bourne Identity specifically showcases Filipino martial arts (Bowman 2013b).
} 
regarded as a film that is guilty of the 'cultural appropriation' or 'expropriation' of Hong Kong traditions (Hunt 2003; Tierney 2006; Park 2010; Barrowman 2015b).

This list could continue. But already two points can be made. First, that the lines between 'action film' and 'martial arts film' in the Hollywood context are extremely blurred. And second, that within all such films actual dialogue about martial arts is rare, fleeting and scanty. In The Matrix, Neo (Keanu Reeves) wakes up from his software installation and breathlessly announces, 'I know kung fu!' Yet other than a few remarks about fighting skill and strategy, this is close to the pinnacle of martial arts dialogue in the film. And the response from Morpheus (Laurence Fishburne) is not, 'Please tell me all about it', but rather, 'Show me'.

Another significant limit case is the classic 1987 cop actioner Lethal Weapon. Early in the film, veteran cop Roger Murtaugh (Danny Glover) tries to engage his undesirable new partner Martin Riggs (Mel Gibson) in conversation, saying, in reference to his Los Angeles Police Department personnel file, '[the] file also said you're heavy into martial arts, taiji and all that killer stuff. I suppose we have to register you as a lethal weapon."

Of course, Lethal Weapon definitely has at least one foot too far into our exclusion zone to be classed as a 'non-martial arts film'. But the way it positions taiji as 'killer stuff' is interesting. This is because, as I have discussed at length elsewhere, taiji is also a kind of 'limit case' martial art. By dint of its complex history, by far the majority of taiji practitioners have little inkling of its combat applications and even less ability to apply them in either free or rule bound sparring or combat (Wile 1996; Frank 2006; Bowman 2015a, 2016, 2017b). Overwhelmingly, taiji is predominantly associated in popular consciousness with calm, soft, flowing, meditative solo sequences. But Lethal Weapon presents taiji as the very thing that makes its eponymous 'weapon' lethal.

\section{Libidinal Cases}

Another slightly less limit case film treats taiji very differently. The 1985 'coming of age' teen wrestling film Vision Quest (also known as Crazy for You) positions taiji as precisely an esoteric, meditative, restful, relaxing endeavour. But in Vision Quest this more typical 'feminized' depiction of taiji comes with a twist. In the scene in which taiji appears, Louden Swaine (Matthew Modine) is delivering room service to a travelling salesman, called Kevin (R.H. Thomas).

\footnotetext{
${ }^{4}$ These lines of dialogue are technically unforgettable, in that it is from them that the film itself, all of its sequels, and the recent TV serials get their name. Thanks to Kyle Barrowman for pointing this out to me.
} 
The salesman is practicing taiji in the hotel room when Louden arrives, and the two engage in conversation about it: ${ }^{5}$

Louden: What is that stuff?

Kevin: Taiji. National form of exercise in China. [Signing the room service receipt] I'll, uh, put your tip on this, ok?

Louden: Can you get a workout that way?

Kevin: 800 million Chinese can't be wrong. It's mainly a matter of getting the mind into the muscles. I use it a lot when I'm on the road. It helps me sleep like a baby.

Louden: Really? I'm on like a 600-calorie-a-day diet and working out like a madman. I'm so wired when I hit the rack, I can't sleep at all. I lie there for about, I don't know, six hours thinking about my life and stuff before I finally drop off.

Kevin: My name is Kevin.

Louden: Louden. Louden Swain.

Kevin: [Louden turns to leave] Let me show you how it's done, Louden. [Louden turns back] It'll help you sleep.

Louden: All right.

Kevin: Why don't you stand there. Face this way. Just sort of catch me out of the corner of your eyes. [Louden stands next to Kevin] Ok, now breathe in. Raise the arms. Keep the movements slow, fluid. Breathe out. Shift your weight to the left. Step onto the right. Sort of stack your hands like that over the knee. Now step back to the left. [Kevin moves over by Louden to help him with his form] Move your arms. Step back to the left. Stack your arms the other way. Step out.

[Kevin's hands, which were initially guiding Louden's arms, move lower on his body. Then his right hand slides up Louden's right leg, at which point Louden flinches and moves away]

Louden [Flustered]: I think I got it now. I'll try it on my own when I get a chance.

Kevin: Do you want to come up later when you're off-duty?

Louden: No. [Louden picks up the bill off of the dresser and backs away towards the door] I don't think so, I got to get home. I'm in training.

Kevin: Training, huh? What sport?

Louden: Wrestling.

Kevin: Wrestling? You know, I sell sporting goods for a living. As a matter of fact, I carry a good line of wrestling shoes.

Louden: [Leaving hurriedly] Just leave the tray by the door when you're finished.

${ }^{5}$ The scene from which the following dialogue has been transcribed can be viewed in full here: https://www.youtube.com/watch?v=5f_MzPVuBq0 
There is much that is interesting about both the dialogue and the action in this scene. But one thing that leaps out is the association of taiji practice with homosexuality, especially because here it functions as a pretext for and gateway to attempted seduction. This could be because of a perceived narrative need to set up a clear counterpoint or foil for what the film wishes to construct as the more masculine activity of wrestling. In other words, the lead character's adverse reaction to homosexual advances can be taken as a device to clarify his heterosexuality - as if to reassure viewers, once more, that despite his engagement in wrestling he is not homosexual. The perceived necessity of such a scene could relate to a common representational problem with wrestling: As many commentators have noted in different contexts, the appearance of wrestling and grappling can often come to seem a little too similar to the appearance of amorous lovemaking for (heteronormative or homophobic) comfort (Downey 2014; Bowman 2017b).

So, the semiotic function is that an already 'feminine' (because 'gentle' and 'Eastern' [Said 1978]) taiji becomes a device of homosexual seduction that Louden must reject. This further clarifies the heterosexuality both of himself and of wrestling. Yet, his final reaction after running away from the hotel room is odd. After racing along the corridor and pressing the button for the elevator, Louden throws himself down to the floor and executes a number of rapid push-ups. The peculiarity of this ostensibly comic act seems to undermine the attempt to safely exclude him from the realm of homoerotic investment. His panicked push-ups have an air of desperation about them - as if he has to do something - anything - to channel his intense feelings (whatever they might be) into a kind of sublimated and socially acceptable form. ${ }^{6}$

This sexual dimension takes us smoothly into another interestingly odd and uncomfortable scene. This is a scene in Stanley Kubrick's adaptation of Lolita (1962), in which Clare Quilty (Peter Sellers) discusses judo with a hotel manager, called Mr. Swine: ${ }^{7}$

Quilty: Mr. Swine, do you mind if I ask you a sort of personal question?

Swine: Sure, go ahead.

Quilty: What is a guy like you doing in a job like this?

Swine: What do you mean?

Quilty: Well, you just don't seem to be the type.

Swine: [Laughs] Well, as a matter of fact, I was an actor.

Quilty: I knew it, I knew it. [He turns to his female companion] Didn't I say to you? [He turns back to Mr. Swine] When I first saw you, there was something about you, a sort of aura that all actors and actresses have.

\footnotetext{
${ }^{6}$ The counter to this interpretation, however, is to recall that Louden is presently 'working out like a madman', in order to cut weight; so he would have been acting like this while waiting for the elevator no matter what had just happened. Thanks again to Kyle Barrowman here.

7 The scene from which the following dialogue has been transcribed can be viewed in full here: https://youtu.be/SX6vrnz5tJY.
} 
Swine: Well, since you're a playwright, uh, maybe you could use me sometime, hmm?

Quilty: Yeah, maybe I could - use you - sometime. [He laughs to himself but then gathers himself] Mr. Swine, what does an actor-manager do with his spare time in a small town like this?

Swine: Well, I don't have much spare time, but...I swim, play tennis, lift weights. Gets rid of the excess energy. [He looks at Quilty's female companion and then back at Quilty] What do you do with your excess energy?

Quilty: [He looks up at his female companion] Well, we do a lot of things with my excess energy. [He looks back at Mr. Swine] I'll tell you one of the things we do a lot of, that's judo. Did you ever hear about that?

Swine: [Chuckles with a sort of surprise] Judo? Yes, I've heard about it. You do judo with the lady?

Quilty: Yeah, she's a yellow belt, I'm a green belt; that's the way nature made it. What happens is she throws me all over the place.

Swine: She throws you all over the place?

Quilty: Yes. What she does, she gets me in a sort of thing called a sweeping-ankle throw. She sweeps my ankles away from under me and I go down with one hell of a bang.

Swine: Doesn't it hurt?

Quilty: Well, I sort of lay there in pain but I love it. I really love it. I lay hovering between consciousness and unconsciousness. It's really the greatest. [They both chuckle]

In this scene, we encounter martial arts combat training depicted as both heterosexual and yet somewhat creepy and uncanny - somewhere between violence and sexuality, somewhere most likely connected with sadomasochism. The perversion hinted at here derives from the impropriety, uncanniness, or 'un-homeliness' ${ }^{8}$ of transgressing so many cultural lines and norms at once: The publicly-policed borderlines between pleasure and pain, sexuality and violence, exercise, competition, health, sadism and masochism - and, moreover, talking about it in this 'double entendre' manner with a complete stranger, of the same sex, quite flirtatiously, while 'the lady' is actually present.

As mentioned, wrestling, grappling and ground-fighting already struggle semiotically because they transgress so many visual and spatial norms that police male to male proximity and interactions (Downey 2014; Bowman 2017b). ${ }^{9}$ The 'double entendre' insistence of this uncanny proximity to heterosexual sex, but

${ }^{8}$ In the original German, Freud's term 'uncanny' is 'unheimlich', which can also be translated as 'unhomely'.

${ }^{9}$ The situation is not helped by the fact that the most popular form of ground-fighting in the world today is known as Brazilian Jiu-Jitsu, a name that is reduced to the acronym 'BJJ'. All of this seems to render it as apparently 'crying out' to become the butt of sexual innuendo and homophobic and misogynistic sleights, affronts and verbal attacks. 
here with a male 'witness' (voyeur) present, amplifies and twists (or queers) it further.

As such, our first two legitimate examples of dialogue about martial arts in non-martial arts films have sexualised it, specifically via discussions of dealing with 'excess energy'. The travelling taiji practitioner in Vision Quest is gay (and predatory). The two men discussing judo training with a woman in Lolita seem to revel in the perverse hetero, bi and homosexual innuendos involved in talking about it.

As a side-note (with reference to films that fall within the exclusion zone), we can note that it has so far only been in the action films mentioned that martial arts are presented as non-sexually exciting and conventionally cool. In Lethal Weapon, Riggs is the crazy, suicidal, 'lethal weapon' martial artist cop and former soldier. In The Matrix, Neo gasps with excitement about suddenly knowing kung fu. The crew of The Nebuchadnezzar who watch Neo fight with Morpheus show us how to react properly - with amazement and excitement and delight at the combatants' skills. So, the spectrum of value emerging here runs from sexual perversion to heteronormative hypermasculinity. Some films try to police the border between these realms. Others regularly traverse it.

\section{From Kinky to Kingly to General}

Consider Charlie Rogers (Elvis Presley) in Roustabout (1964). Charlie is about start his motorcycle to leave when a group of 'tough guy' college kids accost him, their aim being to 'get him': ${ }^{10}$

Student \#1: Is that your 'cycle? [Pronounced 'sickle']

Charlie: You ought to stop reading those hot rod magazines, buddy. 'Cycle is out. It's either bike or motorcycle.

Student \#2: 'Made in Japan', huh?

Charlie: That's right. Made in Japan.

Student \#2: What's the matter? Aren't American 'cycles good enough for you?

Charlie: You don't dig world trade, college boy, after all the economics they tried to shove into you?

Student \#3: Get off, buddy.

Charlie: [Charlie gets off and readies himself for the inevitable attack. Students \#1 and \#3 try to assault him, but he fights them off with deft karate blocks and strikes. He then turns his attention to Student \#2, the only one still standing] Come on! Come on!

\footnotetext{
${ }_{10}$ The scene from which the following dialogue has been transcribed can be viewed in full here: https://www.youtube.com/watch?v=8K98R2VWHCM
} 
Student \#2: [He begins to back away with his hands up waving Charlie off] No, no! That's karate!

Charlie: That goes with the 'cycle.

Here a young, modern, rebellious, non-traditional, forward-looking Elvis Presley puts paid to the old-thinking 'college boys' by using an unexpected and culturally new style of fighting from Japan called karate. After two attackers have been floored, the third aggressor hesitates. Charlie eggs him on, encouraging him to 'come on', but he says, 'No, no! That's karate!' Here, martial arts skill is unexpected, superlative, foreign, exotic, educated, novel, problem solving to be feared and avoided. Basically, it is masculinising.

It is precisely this hope, fantasy or promise - as depicted in this scene in Roustabout - of attaining a kind of 'phallic agency' by way of achieving relative invincibility that has attracted many to martial arts practice. The desire is the desire for potency, agency, confidence, competence, plenitude, and so on. Traditionally, this has been called masculine, of course. However, eventually, the girls have been allowed to arrive. After two Street Fighter films with Sonny Chiba (The Street Fighter [1974] and Return of the Street Fighter [1974]), Sister Street Fighter (1974) finally arrived. After three Karate Kid films (The Karate Kid [1984], The Karate Kid Part II [1986], The Karate Kid Part III [1989]), The Next Karate Kid (1994) was a girl. And so on. Unfortunately, this is not the place to engage with gender issues adequately. ${ }^{11}$ The point is that the skill of Elvis in Roustabout exemplifies precisely the kind of hopes that many people have about martial arts.

This is certainly what drives the 32-year-old layabout Kip (Aaron Ruell) to want to check out the local martial arts club that he has seen advertised on TV in Napoleon Dynamite (2004). ${ }^{12}$ However, in the scene in Napoleon Dynamite in which Napoleon (Jon Heder) and his brother Kip go to the 'Rex Kwon Do' martial arts club in town, we see martial arts and martial artists treated not as calm, cool, collected and hypermasculine, nor as sexually predatory or kinky, but rather, as bundles of neuroses.

The voice of the sensei, Rex (Diedrich Bader), is gravelly in the extreme. He shouts like a drill sergeant. He is arrogant, self-aggrandising and abusive to his potential students. And his martial arts demonstration contains a large number of clichés and classic one-liners. (I am not sure if it was this scene that led people to refer to 'naff' martial arts demonstrations as 'grab my arm demonstrations'. But, certainly, if you were to say to a martial artist that a certain

${ }^{11}$ Moreover, while this was the Hollywood cinema 'gender chronology', in Hong Kong cinema, it was reversed, with the girls - specifically, the girl, Chang Pei-pei, from King Hu's Come Drink with Me (1966) and Chang Cheh's Golden Swallow (1968) - arriving first and then the guys specifically, Chang Cheh's guys, like Jimmy Wang Yu and David Chiang, before, ultimately, of course, the arrival of the guy, Bruce Lee - taking over later. Thanks to Kyle Barrowman for making this point.

${ }^{12}$ https://www.youtube.com/watch?v=Hzh9koy7b1E 
demonstration was a 'grab my arm demonstration', they would most likely understand what you mean. It evokes a kind of old-fashioned, discredited kind of demonstration, involving unrealistic scenarios and ineffective techniques. Unfortunately, such demonstrations still abound. They are still being given, to this day, and are posted in all seriousness online.) Indeed, the martial arts teacher, Rex, is a composite character, made up of stereotypes and clichés that abound in the world.

Rex declares that to be a martial artist you must 'discipline your self-image'. Rex himself wears stars and stripes pantaloons. This means that, contrary to the orientalist imagery and self-orientalising predilections of many Western martial artists, Rex has disciplined his image in a 'non-traditional' but culturally significant way. The gravelly voice and drill sergeant shout are of course comedic affectations within the film, but they also importantly smack of the military. This is significant because the history of the development of 'Asian' martial arts in the US is a narrative in which the US military features very prominently (Krug 2001). In this context, the stars and stripes clown trousers that Rex is so proud to be wearing reinforce the militaristic/patriotic dimension while adding to it an even more widely ridiculed image: That of the bodybuilder. (There was a long-running fashion for bodybuilders in the 1980s and 1990s to wear incredibly baggy elasticated pantaloons, not too dissimilar to those made famous by MC Hammer in the 1990 music video for his hit song 'U Can't Touch This.)

In these ways, Rex is a composite of images of American drill sergeants, 1980s Bon Jovi-inspired rock fans, and vain tough guys, all coming together in the character of a gaudy insecure jingoistic redneck thug. Rex is a comedy caricature that nonetheless points to all the features that went into the making of one enduring image of the martial artist in the US.

However, Rex is not the only one to talk about martial arts in Napoleon Dynamite. Nor is his way of talking about them the only way. Rex and his hilarious martial art of Rex Kwon Do could easily draw all of our attention, but in actual fact the entirety of Napoleon Dynamite can be read as a film that is deeply and thoroughly infused with an awareness of the status of ideas of martial arts in American teen culture. At the start of the film, Napoleon tries to impress the new kid, Pedro (Efren Ramirez), by telling him that there are a lot of gangs in the school and that some of them tried hard to recruit him - because he has 'pretty decent bo-staff skills'. Later on, Napoleon asks Deb (Tina Majorino) to collect some items of hers that he has been looking after, because, he claims, he can no longer fit his 'num-chucks' [sic] in his school locker.

Indeed, as we learn from his regular mentions of them, the 16-year-old Napoleon is quite heavily fixated on the Asian martial arts weapons the 'bostaff' and 'num-chucks' (nunchaku). His elder brother, Kip, however, is more taken by the call of the cage: He tells Napoleon early on that he is in training to 
become a cage fighter, and it is he to asks Napoleon to pull him on his rollerskates to Rex's 'Rex Kwon Do' club in town.

Both of these fantasy fixations start to wane as the characters become involved in real relationships with girls. Kip stops discussing cage fighting when he hooks up with his new girlfriend LaFawnduh (Shondrella Avery) and switches instead to focusing on cultivating a 'black' ghetto sartorial style. Napoleon stops fretting about bo-staffs and num-chucks when he discovers dancing and especially as his relationship with Deb grows.

In other words, martial arts in Napoleon Dynamite are fantasy resolutions to problems. Napoleon tries to impress Pedro and Deb by claiming bo-staff and nunchaku skills. But, later on, he laments his lack of them. In a memorable scene, Napoleon sets out his answer to the question of what girls want: They want 'skills'. And he feels he doesn't have any. Pedro asks what he means by skills, and Napoleon answers: 'Nunchuck skills...bowhunting skills...computer hacking skills...Girls only want boyfriends who have great skills!' Kip has also given his answer to the same question, having announced early on in the film: 'Napoleon, don't be jealous 'cause I've been chatting online with babes all day. Besides, we both know that I'm training to become a cage fighter'. And, of course, Rex famously challenges everyone with the belligerent rhetorical question, 'You think anybody thinks I'm a failure because I go home to Starla at night?' (Starla being an extremely masculine-looking bodybuilder played by real-life women's bodybuilding champion Carmen Brady).

Martial arts in Napoleon Dynamite are refracted through extant cultural imagery derived from film and TV: Napoleon is interested in the 'classic' martial arts filmic idea of being skilled with Japanese weapons (the bo, the nunchaku); Kip is taken by the 'modern' Western idea of cage fighting; and Rex seems to be saturated in imagery derived from the incorporation of Asian martial arts in US military training.

The vocal style of Rex is not a world away from that of Gunnery Sergeant Emil Foley (Louis Gossett Jr.) in An Officer and a Gentleman (1982), who trains the officer cadets in hand to hand combat. Similar, too, is Sensei John Kreese (Martin Kove) in The Karate Kid, whose dojo is run like a Marine Corps basic training camp and is adorned with images of Sensei Kreese himself when he was actively serving as a Marine.

The Karate Kid is obviously a martial arts film, so we will have to pass over it here. However, An Officer and a Gentleman is not. Nor is it an action film. But martial arts do feature within it, and there is dialogue about them within the film. Therefore, we can give it some attention.

Early on in An Officer and a Gentleman, Zack Mayo (Richard Gere) despatches a belligerent aggressor in a scenario not dissimilar to the one Elvis' Charlie found himself in in Roustabout, although without the cocky sass. To the contrary, Gere's Zack has repeatedly told the aggressor 'I do not want to fight you', and afterwards, despite his friends' joy, amazement and delight in his 
victory ('Did you see that guy's face!?') and sympathy ('He gave you no choice'), Zack is angry at himself: 'There is always a choice!'13

This idea of the trained fighter who wishes to avoid fighting emphasizes, in this case, his 'gentlemanliness'. We could trace this particular construction of gentlemanliness genealogically back to the 'gentlemanly art' of Bartitsu and the jujitsu craze of Victorian Britain, as exemplified by Sherlock Holmes. It can also be traced back to various ideologies of pacifism that are often imputed (often apocryphally) to 'oriental' martial arts - such as Buddhist and Taoist pacifism or classic Confucian gentlemanly ideals.

Sherlock Holmes turned out to have 'some knowledge ... of baritsu, or the Japanese system of wrestling. What Conan Doyle rendered as 'baritsu' was actually called 'Bartitsu'. It initially appears as a retroactive 'deus ex machina' in The Return of Sherlock Holmes 1. The Adventure of the Empty House (1903): Holmes explains upon his return that he used martial arts to save himself during his fight with Moriarty on the Reichenbach Falls (Godfrey 2010). Recent film adaptations have made much of Holmes' martial arts skills, most recently in the form of the rather messy gentlemanly thug Holmes as played by Robert Downey Jr.

With many gentlemen fighters, what led to the development of their skill was an earlier brutalisation. In An Officer and a Gentleman, a flashback shows us that the childhood incarnation of Gere's Zack was beaten up by a gang of local kickboxing kids in a crowded Asian city back street. Hence, we learn his need to develop his own kickboxing skills. They derive from what Sylvia Chong would discuss in terms of 'the oriental obscene' infusing and in part constituting the Western gentlemanly identity (Chong 2012).

Full Metal Jacket (1987) gives us a different creation scenario. Two Marines relaxing in town, photographing a prostitute who is trying to solicit them, have their camera snatched by a Vietnamese thief, who, in a parting display of adrenaline fuelled anger and triumph, turns and performs kicks, finger jabs and strikes in their direction before escaping on a motorbike. One Marine turns to the other and says, 'Wow, did you see the moves on that guy?'14

It is easy to see why the West fell in love with Eastern martial arts: The 'moves' can be spectacular. However, it is not compulsory to fall in love with or in thrall to them - nor with the 'moves' of the other guy. For instance, when the Houston team are preparing for a daunting match in Tokyo against a Japanese team in Rollerball (1975), the management brings in someone to explain that the Japanese players will be using martial arts techniques from karate and (somewhat surprisingly, the Korean art of) hapkido. The reason for the lesson is because 'forewarned is forearmed'. But the team is cynical. Why should they care about Japanese martial arts when they all already know the 'good ol' Houston fist in

\footnotetext{
${ }^{13}$ https://www.youtube.com/watch?v=5er6ufig0uo

${ }^{14}$ https://www.youtube.com/watch?v=Hch3HL8gPTk
} 
the face technique'? ${ }^{15}$ Indeed, in Rollerball, the martial moves of the other are rejected, in favour of sticking with the simplicity and homeliness of the pugilistic approach that they already practice.

\section{Fighting Talk}

Perhaps the rejection of the oriental other that we see in Rollerball is something of an exception. Certainly, in many other films, the oriental otherness of martial arts is fetishized, idealised, and desired. Indeed, even when they haven't actually trained in it at all, some people realise that simply talking about martial arts and claiming to 'know' them can constitute a viable form of self-defence. Eddie Murphy's Billy Ray Valentine exemplifies this in Trading Places (1983), in a comic scene in a prison cell. ${ }^{16}$

In this scene, Billy claims to have fought dozens of police officers who attempted to arrest him the night before. When questioned about why he appeared to be crying when brought into the cell, he claims the police had used tear gas (a substance normally reserved for riot situations) to subdue him. Throughout this scene, what Murphy's character invests in are the ways in which martial arts both look cool and might make you seem scary and offputting to any potential aggressor. The verbal claims to be able to 'do' martial arts might both carry some cultural capital and therefore act as a deterrent.

We see the other side of this logic in an early scene in The Wanderers (1979). Again, it is a new kid's first day at school (Perry, played by Tony Gianos). Joey (John Friedrich) is introducing the new 'kid' (his new found 19-year-old friend-cum-protector) to the gang culture of his school and neighbourhood. Walking along packed school corridors, Joey points to different groups and reels off their names and ethnic characteristics. Irish gangs, black gangs, Italian gangs, etc. Then Joey points out The Wongs. Excitedly, Joey describes them like this: '27 guys all with the last name Wong, all black belts in jujitsu who could kill you with one judo chop!'17

I have known this film and this line for most of my life. For many years, I thought little of it, other than what it is on one literal level designed to make the impressionable viewer think: The Wongs are a cool-looking and formidably tough gang of Asian martial artists. Of course, because of scenes like this, which treat ethnic difference less than 'politically correctly', The Wanderers is now held up in various online charts and YouTube analyses as an example of 'Hollywood racism'. And, of course, Joey is ethnically profiling the gangs. But the gangs are ethnically organised. Indeed, within this framework the Wongs are fulfilling their ethnic stereotype destiny - by being Asians who are martial

\footnotetext{
15 https://www.youtube.com/watch?v=WUSCpZMbPnQ

16 https://www.youtube.com/watch?v=4WMErc1n6Ks

17 https://www.youtube.com/watch?v=GzPeYdeG2co
} 
artists. It needs to be noted that racial tension is part of the dramatic tension, story arc and symbolic order of this film. So, denouncing the film's supposed 'racism' is less interesting than thinking about the matter of Joey's palpable excitement at the idea of them all being 'black belts' who 'could kill you' with one technique.

It was only when racking my brains for filmic examples for this study that I realised that I would be able to make a pedantic aficionado point about the differences between jujitsu and judo, and hence say something about Joey's ignorance. And it was only then that I thought, hang on: Wong? Jujitsu? Judo? The name Wong is Chinese, not Japanese. Jujitsu and judo are Japanese. What is going on here? I confess, to try to learn more, I had to turn to the visuals, not the dialogue, to try to clarify the ethnic situation here - in particular, by turning to the final fight of the film - the huge gang fight on the football field. And, to my eyes, it looks like the Wongs are practicing a Chinese martial art, rather than anything Japanese (although I cannot be sure). Of course, now I could be accused of ethnic stereotyping. But I think it is more interesting to think about the ways in which the film - in the form of Joey - cares not a jot about the actual specificities of whether the Wongs and their martial arts are Chinese or Japanese. Indeed, even if the disjunction between the family name and the ethnic attributions are a knowing joke on the part of the filmmakers, the only thing that the film cares about is the fact that true martial arts skill in a teen-world context makes the martial artists seem fearsome and cool to their non-martial artist peers.

But the martial arts experts who are held in awe are othered. They are presented as readymade and complete. We may ask about the aspirant martial artist, the subject who desires to become an expert. Films often seem to face a problem when it comes to the matter of a character aspiring to become fearsome and cool themselves, via self-cultivation and training. In fact, it seems that, unless this occurs within a martial arts film and is depicted via large doses of training montages, the desire to become a martial artist seems always on the verge of becoming ridiculous. One can 'be' an adept fighter. One can 'be' a martial artist. But if there is desire and training and aspiring, it seems that this is most easily depicted as comic, eccentric, perverse, and weird.

Of course, some non-martial arts films do occasionally associate martial arts training with higher cultural values. At the end of Once Were Warriors (1994), for instance, the central characters - a mother and two brothers (Beth [Rena Owen], Nig [Julian Arahanga], and Boogie [Taungaroa Emile]) - come together as a family. The film is set in a poverty ravaged Maori community, and all kinds of violence have been horrifically and relentlessly present throughout. The older brother, Nig, has embraced a close-knit gang community and is covered in Maori tattoos. By contrast, by the end of the film, the younger brother, Boogie, has found a kind of salvation in traditional Maori martial arts training. In an affectionate scene, the older of the brothers asks the younger whether he'd like some similar tattoos. 'No thanks', says the boy, 'my tattoos are on the inside?. 
However, even 'higher' cultural values can easily be mocked - especially if there is any kind of ethnic, racial or cultural cross-dressing involved (Bowman 2010b). If the last vestiges of all-but-lost Maori arts are presented as a symbol of a tiny glimmer of hope for the ravaged community in Once Were Warriors, any kind of cross-ethnic cultural performance of another culture's art is always going to raise eyebrows and questions. Hence, Gaylord Focker's (Ben Stiller) father, Bernie, played by Dustin Hoffman, in Meet the Fockers (2004), practices capoeira. Capoeira is an afro-Brazilian martial art that has a great deal of cultural and political significance as a postcolonial practice, and its practitioners and the academics who study it invest heavily in its cultural significance (Griffith 2016). But, in Meet the Fockers, capoeira is reduced to the term 'dance fighting. ${ }^{18}$ It is not 'proper fighting', it is 'dance fighting'. The white man who invests in it is obviously a certain 'type'. What kind of type? As I have argued about this before, in the words of the 1998 Offspring song 'Pretty Fly For a White Guy', the white cultural cross-dresser or cross-performer is always going to be regarded as a 'wannabe' (Bowman 2010b).

The 'wannabe' is neither one thing nor another, neither this nor that, neither here nor there. The wannabe wants (to be) something they are not. Sometimes, the desired thing itself is impossible (invincibility, for example). Other times, the wannabe cannot be, attain or obtain what they desire because doing so is impossible (changing ethnicities, for example). Such a person is going to find themselves scorned, spurned, ridiculed, reviled, or at best pitied.

\section{Conclusion}

This work has set (and transgressed) some artificial/schematic parameters in order to focus on the margins of martial arts discourse and to see what might be gleaned about the discursive status of martial arts. Drawing the line in such an unusual place required us to give some attention to an area of martial arts marginalia that might otherwise remain ignored, with all of the attention of martial arts studies (or cultural studies of martial arts) going to 'proper' contexts of martial arts, such as the visual realm of fight choreography or the discursive construction of martial arts in 'proper' martial arts films. Obviously, these are important areas of enquiry. But this chapter imposed a principled exclusion of all things 'proper' and 'obvious' (and inevitably failed to maintain the border: In setting it, we transgressed it, and in setting out what we would not talk about we regularly had to engage with what we said we weren't going to). In doing so, the films we were able to examine suggested that outside of martial arts discourse proper, martial arts have multiple potential significations, and diverse potential values.

Because of the attempt to exclude visual representation and prioritise verbal representation, not many films could be found that fitted the bill comfortably.

18 https://www.youtube.com/watch?v=srV41k0NWgo 
There seem to be very few non-action films that discuss martial arts. This is so even though visual representations of martial arts abound. Nonetheless, what this unconventional foray into the margins of martial arts discourse in film suggests is that discussions of martial arts in non-martial art films tend to relate to fantasies and desires in relation to identities that originate or proliferate in the face of feelings of insecurity, at transitional times, and in transitional contexts. In Lacanian terms, they emerge and circulate as (if) answering a lack or a need.

This explains why those who are believed to 'have it' or 'be it' can be revered as 'real men'. Conversely, those who are seen to be striving or fantasising about becoming 'it' or getting 'it' can so easily be regarded as lacking, as wanting, as losers. As Kaja Silverman argued of the Lacanian understanding of subjectivity: Identity, fantasy and desire are so complexly intertwined and imbricated that, in Lacanian terms, one cannot really discuss one of these dimensions without discussing the others (Silverman 1983, 6). The fact that non-psychoanalytic discourses do discuss identity without discussing fantasy and desire helps to put things like martial arts practice in such an odd position. Taiji and judo are both 'not meant' to be sexual, and yet can so easily be depicted as uncannily, almost, or also so. This internet meme from many years ago encapsulates if not the full constellation of possibilities then at least some key parallax views:

\section{When I tell people I train Brazilian Jiu-Jitsu:}

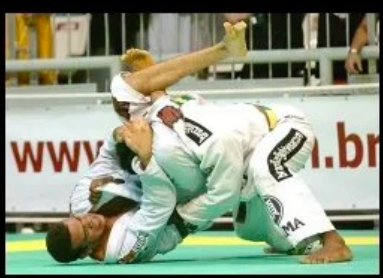

What I think I do.

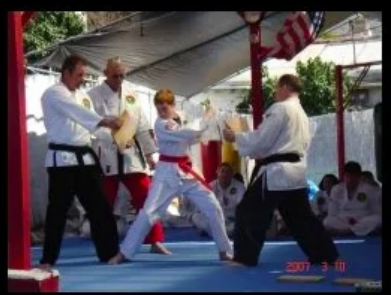

What my mom thinks I do.

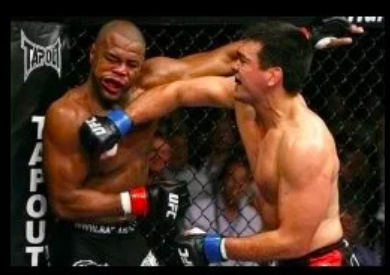

What my coworkers think I do.

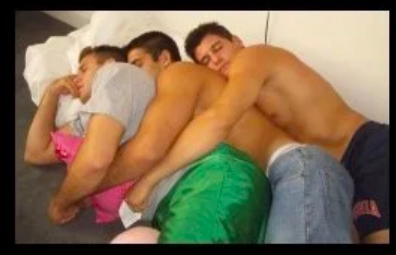

What boxers and kickboxers think I do.

reddit.com/r/bjj 
There are more potential reasons why, discursively or culturally, martial arts inevitably lie between a rock and a hard place - neither this nor that, both this and that. For instance, they are peculiar structured responses that seek to 'manage' the problem of physical violence in its own terms. However, physical interpersonal violence is itself of a peculiar status: Physical violent responses to the threat or reality of physical violence are rarely regarded as the best or most intelligent possible responses. They are most easily regarded as aberrant responses to aberrant situations. After all, fighting is what children do, what parents enjoin them to grow out of. Attacking others in day to day life is rarely regarded as a mature or balanced thing, even if others attack or threaten to attack you. In (most) 'civilised societies', the state has accrued (almost) all of the rights to the legitimate dispensation and management of violence. Adults should not 'normally' settle differences with a fist fight. To some, such actions signal being 'more' than an average person; to others, it signals being 'less', or abnormal.

Martial arts thrive in liminal spaces, spaces of becoming: Becoming adult, becoming competent, capable, 'strong', and so on. Perhaps 'most properly', martial arts are 'transitional objects' in the psychoanalytic sense, or 'vanishing mediators' in Fredric Jameson's sense of something that enables a new situation to emerge (whether that be adulthood or heteronormative partnering), that must recede and be forgotten once the new condition has been reached. As both one of Wittgenstein's and one of Buddhism's aphorisms puts it in different ways: Once you've used the tool to do the job, you don't lug it along with you; you just put it down and move on.

But martial artists don't move on. To this extent, they fail to become 'normal', or at least defer it. Unless they turn into Rex, this could become socially acceptable. However, unless martial arts training happens in childhood, at the start of the process, the aspirant, desiring martial artist can appear ridiculous - whether 'funny peculiar' or 'funny ha-ha'. This is because martial arts involve effort, process and 'becoming': They have a kind of originary lack inscribed in their heart. The very desire to do martial arts, and practicing martial arts with the aim of becoming different, more, better, other, etc., signals the presence and workings of lack, desire, insecurity, and incompletion. Children can play at martial arts and become more competent. Adults are meant to be complete. The adult who desires martial arts mastery too late in life diverges from the norm.

Martial arts signal liminality, they involve crossing multiple borders at once, the desire to become unproblematically powerful (Elvis' Charlie) or to have hidden depths and untold skills (Richard Gere's Zack), but the entire discourse is haunted by the risk of remaining in the realms of murky conscious or unconscious desires and unclear investments, like those of the predatory Kevin, the insecure Rex, Napoleon and Kip, or the uncannily creepy Quilty. One suspects that such eccentric and idiosyncratic - tragicomic, laughable, 
weird - characters offer us more insight into what it is to try to become or be something than do the alpha males on screen who perform the supposed ideal and construct the supposed norm. But maybe, 'really', people are 'really' a lot less like Elvis' Charlie or Richard Gere's Zack Mayo, and considerably more like Napoleon Dynamite or Eddie Murphy's Billy Ray Valentine: All talk. 